\title{
A Glycomics Platform for the Analysis of Permethylated Oligosaccharide Alditols
}

\author{
Catherine E. Costello, ${ }^{\mathrm{a}}$ Joy May Contado-Miller, a and John F. Cipollo ${ }^{\mathrm{a}, \mathrm{b}}$ \\ ${ }^{a}$ Mass Spectrometry Resource, Department of Biochemistry, Boston University School of Medicine, Boston, \\ Massachusetts, USA \\ ${ }^{\mathrm{b}}$ Center for Biologics Evaluation and Research, Division of Bacterial, Parasitic and Allergenic Products, Food \\ and Drug Administration, Bethesda, Maryland, USA
}

This communication reports the development of an LC/MS platform for the analysis of permethylated oligosaccharide alditols that, for the first time, demonstrates routine online oligosaccharide isomer separation of these compounds before introduction into the mass spectrometer. The method leverages a high-resolution liquid chromatography system with the superior fragmentation pattern characteristics of permethylated oligosaccharide alditols that are dissociated under low-energy collision conditions using quadrupole orthogonal time-offlight (QoTOF) instrumentation and up to pseudo $\mathrm{MS}^{3}$ mass spectrometry. Glycoforms, including isomers, are readily identified and their structures assigned. The isomer-specific spectra include highly informative cross-ring and elimination fragments, branch position specific signatures, and glycosidic bond fragments, thus facilitating linkage, branch, and sequence assignment. The method is sensitive and can be applied using as little as $40 \mathrm{fmol}$ of derivatized oligosaccharide. Because permethylation renders oligosaccharides nearly chemically equivalent in the mass spectrometer, the method is semiquantitative and, in this regard, is comparable to methods reported using high field NMR and capillary electrophoresis. In this postgenomic age, the importance of glycosylation in biological processes has become clear. The nature of many of the important questions in glycomics is such that sample material is often extremely limited, thus necessitating the development of highly sensitive methods for rigorous structural assignment of the oligosaccharides in complex mixtures. The glycomics platform presented here fulfills these criteria and should lead to more facile glycomics analyses. (J Am Soc Mass Spectrom 2007, 18, 1799-1812) @ 2007 American Society for Mass Spectrometry

$\mathrm{I}$ is estimated that up to $50 \%$ of all proteins are glycosylated [1, 2]. Protein glycosylation is involved in many, if not most, biological processes and there is extensive literature that documents its involvement in diverse areas such as cell-cell recognition, cell-extracellular matrix interactions, tissue development, immune response, host-pathogen recognition, protein folding editing control, and protein stability [3-6]. Glycans are not directly encoded in the genome. Therefore, their structures cannot be predicted strictly by a reading or manipulation of the genetic code as is the case with nucleic acids and proteins. Although it seems unlikely that the full range of potential structures is realized in nature, an oligosaccharide of only six monosaccharide components could theoretically give rise to greater than $1 \times 10^{12}$ chemically distinct structures $[7,8]$. This is many orders of magnitude higher than that of a hexapeptide because, as cyclic polyols, the components of oligosaccharides have more linkage points, the resulting structures can be branched, and linkages can be formed in either an $\alpha$ or $\beta$

Address reprint requests to Dr. J. F. Cipollo, Food and Drug Administration, Center for Biologics Evaluation and Research, Division of Bacterial, Parasitic and Allergenic Products, 8800 Rockville Pike, Building 29A, Bethesda, MD 20892-0001, USA. E-mail: John.cipollo@fda.hhs.gov anomeric configuration. Therefore, structural identification of oligosaccharides presents a considerable technical challenge.

The development of analytical methods for routine analysis of oligosaccharides has lagged behind those of proteins and nucleic acids. Often the relevant biological questions dictate that the amount of glycan material available for analysis is extremely limited. Furthermore, the glycans are almost always present as a mixture of closely related structures, only a few of which may have biological activity. Aberrant glycosylation, e.g., in a disease state, can be dramatic, such as loss of nearly an entire class or subclass of glycans, or more subtle, such as loss of only a few isomers within a subclass [3,9-11]. Naturally, the ability to detect the dramatic as well as the subtle changes in extremely limited sample amounts will be required as questions of glycomic consequence are considered. Ultimately, this means that complete structural assignment of all the glycans in complex mixtures must be accomplished over a wide dynamic range, often with limited sample amounts. With the growing interest in glycomics, clearly more sensitive and informative platforms must be developed for oligosaccharide and glycoconjugate structural investigation. 
Liquid chromatography mass spectrometry (LC/ MS) has been used in various configurations for oligosaccharide analysis. The LC/MS method can be considered to have three components. While the more obvious components are the LC and MS instruments, the third variable is the analyte itself, in that the choice of the particular derivative to be used can have a dramatic effect on spectral properties.

Permethylation of oligosaccharides increases their ionization efficiency up to 20-fold [12]. The tandem mass spectra of permethylated oligosaccharides contain a higher abundance of cross-ring fragments than their native counterparts, thus allowing a higher probability of linkage assignment [13-16]. Elimination of the C3 substituent from HexNAc residues in permethylated glycans is useful for linkage assignment [17-19]. Also, a chemical signature for branch substitution is inherent in permethylated oligosaccharide spectra, since fragments that expose formerly internal residues in newly formed terminal positions are $14 \mathrm{Da}$ lower in mass at each former branch site due to the presence of a hydroxyl group at the glycosidic cleavage site, whereas all the hydroxyls of native terminal units are methylated. Permethylation also imparts additional hydrophobic character to oligosaccharides, thus making them more amenable to the LC methods most suitable for LC/MS applications, which require organic solvents and low buffer concentrations. Permethylated derivatives of oligosaccharides have been extensively studied by matrixassisted laser desorption/ionization (MALDI) and electrospray ionization (ESI) tandem MS and their fragmentation properties are well understood. Surprisingly little effort has been made to develop LC/MS methods for these compounds. This, in part, may be due to their lack of a chromophore and the consequent barrier to off-line methods development. LC/MS methods have been reported for analysis of permethylated derivatives using reversed-phase chromatography [20, 21], but improvements on these methods are desired, to provide isomer separation.

Many liquid chromatography formats have been used for separation of oligosaccharides. Some examples of these include normal phase (NPC) [22], reversedphase (RPC) [23, 24], porous graphitized carbon (PGC) [25], hydrophilic interaction (HILIC) [26], ion-exchange (IEC) [27], and high $\mathrm{pH}$ anion exchange (HPAEC) [27] chromatographies. PGC, HILIC and HPAEC provide superior resolution of oligosaccharides and allow separation of some isomers. Each has been employed in LC/MS applications for separation of native glycans and/or glycans derivatized at the reducing end [27-31]. PGC is an attractive candidate for application to characterization of permethylated glycans as it has been reported to provide excellent separation of analytes ranging from highly polar to hydrophobic.

Naturally, it would be advantageous to leverage the superior information content of permethylated oligosaccharide fragmentation spectra with an LC/MS platform capable of isomer differentiation. Although
LC/MS analysis of permethylated glycans has been reported [20, 21, 32], until this report, LC/MS isomer separation of these compounds has not been demonstrated. The capacity to separate permethylated oligosaccharide isomers by LC before infusion into the mass spectrometer can make their analysis more facile. Here we report the first separation and identification of permethylated oligosaccharide isomers using an LC/MS platform. This has been accomplished using a PGC LC system, in combination with the further separation capacity of the mass spectrometer. This platform should significantly enhance the capacity for the bioanalyst to identify oligosaccharides in complex mixtures.

\section{Experimental}

\section{Materials}

Ribonuclease B, fetal calf serum fetuin, bovine articular cartilage decorin and corn syrup malto-oligosaccharides were from Sigma-Aldrich (St. Louis, MO). All reagents were ACS grade or higher. Recombinant PNGase F was expressed and purified in-house.

\section{Oligosaccharide Release and Reduction}

$\mathrm{N}$-glycans were released from protein by treatment with PNGase $\mathrm{F}$ at $4000 \mathrm{U} / \mathrm{mL}$ at $37^{\circ} \mathrm{C}$ for $16 \mathrm{~h}$. The digest solution contained $0.1 \%$ sodium dodecyl sulfate and $0.75 \% \mathrm{NP}-40$ in $50 \mathrm{mM}$ ammonium bicarbonate $\left(\mathrm{NH}_{4} \mathrm{HCO}_{3}\right)$ at $\mathrm{pH}$ 8.0. After release, the oligosaccharides were purified by solvent extraction as previously described [33]. Briefly, detergent and salts were removed by solvent precipitation in $80 \%$ acetone at $\mathrm{pH}$ 5.5. The released oligosaccharides were purified by solvent extraction in $50 \%$ methanol acidified to $\mathrm{pH} 5.5$ with drop-wise addition of acetic acid. Dried glycan samples $(1$ to $100 \mu \mathrm{g})$ were placed in $200 \mu \mathrm{L}$ of $0.1 \mathrm{M}$ $\mathrm{NaOH} / 1 \mathrm{M} \mathrm{NaBH}$ for $1 \mathrm{~h}$ at ambient temperature. Borate was removed by rotary evaporation from acidified methanol (1\% acetic acid).

Bovine articular cartilage was processed as follows. To $50 \mathrm{ug}$ of decorin proteoglycan was mixed $10 \mathrm{uL}$ water, $2 \mathrm{uL} 1 \mathrm{M}$ tris- $\mathrm{HCl}$ buffer ( $\mathrm{pH} 7.4), 1 \mathrm{uL} 1 \mathrm{M}$ $\mathrm{NH}_{4} \mathrm{OAc}$, and $20 \mathrm{mU}$ of chondroitinase $\mathrm{ABC}$ and digestion was allowed to proceed at $37^{\circ} \mathrm{C}$. Completion of the reaction was monitored by size exclusion chromatography until a single peak of the core protein was observed. This required a total of $60 \mathrm{mU}$ of chondroitinase $\mathrm{ABC}$, where $20 \mathrm{mU}$ of the chondroitinase was added every $8 \mathrm{~h}$. The mixture was allowed to digest for a total of $24 \mathrm{~h}$ after which the reaction was stopped by boiling the mixture for $2 \mathrm{~min}$. Decorin core protein was purified using a Superdex Peptide 3.2/30 column (Amersham Biosciences, Piscataway, NJ), which was equilibrated in $10 \% \mathrm{ACN}, 0.1 \mathrm{M}$ ammonium acetate at $100 \mathrm{uL} / \mathrm{min}$ and with detection at $232 \mathrm{~nm}$. N-glycans were release from $25 \mu \mathrm{g}$ of dried decorin core protein as described above. 
C. elegans $O$-glycans were released from whole nematode extracts as previously described [34]. Briefly, glycans were released by reductive $\beta$-elimination in $0.1 \mathrm{M} \mathrm{NaOH} / 1 \mathrm{M} \mathrm{NaBH}_{4}$ at $60{ }^{\circ} \mathrm{C}$ for $16 \mathrm{~h}$ followed by neutralization with drop-wise addition of glacial acetic acid. The mixture was passed over a $10 \mathrm{~mL}$ column of Dowex 50W cation exchange resin (hydrogen form, Sigma-Aldrich) and oligosaccharide material was eluted with water. Borate was removed as tetramethylborate by rotary evaporation from acidified methanol (1\% glacial acetic acid). After reconstitution, the samples were applied to a $10 \mathrm{~mL}$ column of AG1x-2 acetate anion exchange resin. Neutral glycans were eluted with water and acidic ones eluted with $100 \mathrm{mM} \mathrm{NH}_{4} \mathrm{OAc}$. The pools were dried by rotary evaporation.

Released $\mathrm{N}$ - and $\mathrm{O}$-glycans were further purified using porous graphitized carbon (PGC) cartridges (Thermo Electron, Waltham, MA). The cartridges were pre-wet with $100 \%$ acetonitrile and rinsed sequentially with two $\mathrm{mL}$ each of $60 \%, 30 \%$, and $0 \%$ acetonitrile, all of which contained $0.1 \%$ trifluoroacetic acid. The glycans were applied to PGC in water, washed extensively with $0.1 \%$ trifluoroacetic acid and eluted by application of $1.5 \mathrm{~mL}$ of $30 \%$ acetonitrile in $0.1 \%$ trifluoroacetic acid. The samples were then dried in a Savant speed evacuation device (Thermo).

\section{Permethylation of Oligosaccharides}

Oligosaccharides were permethylated using the method of Ciucanu and Kerek [35] with minor modifications as described previously [36]. Sample recovery was $70 \%$ to $95 \%$ based on phenol sulfuric acid assay for neutral hexose and/or peak intensity on MALDI-TOF MS analysis using permethylated oligosaccharide standards. Sample purity and suitability for LC/MS analysis was verified by MALDI-TOF MS on a Reflex IV instrument (Bruker, Billerica, MA), using 2,5-dihydroxybenzoic acid as matrix and a nitrogen laser $(337 \mathrm{~nm}, 3 \mathrm{~ns}$ pulse width).

\section{Liquid Chromatography/Mass Spectrometry}

Porous graphite liquid chromatographic separation was achieved with either a $2 \times 50 \mathrm{~mm}$ or $0.320 \times 100 \mathrm{~mm}$ Thermo Hypersil-Keystone porous graphite chromatography (PGC) column (Thermo) and a Beckman Coulter System Gold 125 solvent module (Mississauga, Ontario, Canada). Solvent A was $0.05 \%$ formic acid. Solvent B was 1:1 acetonitrile: isopropanol (vol:vol) in $0.05 \%$ formic acid. The gradient was 30\% Solvent B for $5 \mathrm{~min}, 30 \%$ to $65 \%$ Solvent B over $5 \mathrm{~min}, 65 \%$ to $85 \%$ Solvent B over $50 \mathrm{~min}, 85 \%$ to $100 \%$ Solvent B over 5 min, $100 \%$ Solvent B for $10 \mathrm{~min}$, return to $30 \%$ Solvent $B$ in $0.1 \mathrm{~min}$ followed by equilibration to original conditions for $5 \mathrm{~min}$. The entire gradient program was $80.1 \mathrm{~min}$. This gradient was used for all experiments presented. The column eluate was delivered through a postcolumn split to a QStar Pulsar-i quadrupole orthog- onal time-of-flight mass spectrometer (Applied Biosystems/SCIEX, Framingham, MA) equipped with a Turbospray ion source. The postcolumn split flow rate to the spectrometer source was 10 and $5 \mu \mathrm{L} / \mathrm{min}$ for the 2-mm and 320- $\mu \mathrm{m}$ diameter columns, respectively. Postcolumn infusion of formic acid was used in a final infused concentration of $1 \%$. Ten percent formic acid was prepared in methanol and infused at 1:10 (vol:vol). Data-dependent acquisition experiments were performed using Analyst software (Applied Biosystems). Include and exclude lists were used to target select ions for CID experiments. Collision voltages were applied automatically according to a linear calibration curve determined for $1+, 2+$, and $3+$ charge states using permethylated oligosaccharide standards. The mass spectrometer parameters were as follows for $\mathrm{MS}^{2}$ experiments: DP1 75.0 V, FP 245.0 V, DP2 30.0 V, CG 3.0 psi, IRD 6.0 V, IRW 5.0 V, GS1 5.0 psi, GS2 10.0 psi, CUR 12.0 psi and the ion spray voltage was between 4000 and $4500 \mathrm{~V}$. Collision gas was Ar. For pseudo $\mathrm{MS}^{3}$ experiments the following parameters were used: DP1 130.0 V, FP 300.0 V, DP2 40.0 V, CG 3.0 psi, IRD 6.0 V, IRW 5.0 V, GS1 5.0 psi, GS2 10.0 psi, CUR $12.0 \mathrm{~V}$.

\section{Results and Discussion}

\section{Rationale and Key Experimental Observations}

Reduced and permethylated malto-oligosaccharides, RNase B released $\mathrm{N}$-glycans, articular cartilage released $\mathrm{N}$-glycans, and $\mathrm{C}$. elegans whole nematode extract released $\mathrm{O}$-glycans were analyzed. This selection provided linear, high mannose, complex, hybrid, and short, highly branched oligosaccharides for study. Reduction was performed to avoid separation of the $\alpha$ and $\beta$ anomers of the permethylated oligosaccharides on the PGC columns, as well as to enable distinction of potentially isobaric fragment ions. The LC system used here was optimized for the oligosaccharides presented. However, an increased amount of isopropanol can be used in Solvent B to provide better chromatographic properties for more highly retained permethylated oligosaccharide alditols. The branch isomers containing Fuc had clearly unique retention times, whereas positional isomers that varied in the location of Man had retention times that were more similar to one another. The peak shapes of sialylated glycans tended to be broader than were those of other compounds having similar masses (data not shown). For glycans such as those released from $\alpha$-one acid glycoprotein, where a high proportion of higher molecular weight glycomers occurs, Solvent B can be replaced with 2:1 isopropanol: acetonitrile. Essentially the same gradient can be used. Typically, these conditions allow resolution of more glycomers than that obtained with 1:1 isopropanol:acetonitrile where these tend to elute as an unresolved group during the $100 \%$ Solvent B ramp (data not shown). 
In this study some key fragment ions were observed, and these reiterated trends that have been observed previously in fragmentation patterns of permethylated glycans. The branching pattern of the oligosaccharides could be deduced from CID spectra containing fragments bearing a mass signature of $-14 \mathrm{Da}$ for each lost branch. In samples containing Hex and HexNAc residues, abundant ${ }^{0,4} \mathrm{~A},{ }^{1,4} \mathrm{~A},{ }^{1,3} \mathrm{~A}$, and ${ }^{3,5} \mathrm{~A}$ cross-ring fragments were often observed, thus allowing the assignment of 1-2, 1-4, and 1-6-linkages [37, 38]. Elimination at the $\mathrm{C} 3$ of HexNAc was also observed, and provided a chemical signature that could be used to assign C3 substitutions as has been previously reported $[17,18]$. In high mannose and hybrid glycans, secondary fragmentation gave rise to product ions that clearly defined the high mannose portion. In highly branched
O-glycans, fragmentation across the $\mathrm{C} 2-\mathrm{C} 3, \mathrm{C} 3-\mathrm{C} 4$, and C4-C5 bonds was key to structural assignments. Results were highly reproducible in terms of extracted ion chromatogram (XIC) intensity, CID fragment ion intensity, and sensitivity. The nomenclature used is that of Domon and Costello [39]. Monosaccharide symbols are those suggested by Varki et al. [40,41] with some modification allowing for Hex.

\section{Porous Graphite LC/MS of Malto-Oligosaccharides}

As shown in Figure 1a, Glc $_{4-8}$ were well separated when malto-oligosaccharide aliquots of $\sim 300 \mathrm{ng}$ of reduced and permethylated malto-oligosaccharides were analyzed. The CID spectrum of $\mathrm{Glc}_{5}[\mathrm{M}+\mathrm{Na}]^{+}, \mathrm{m} / z$ 1105.64,

(a)

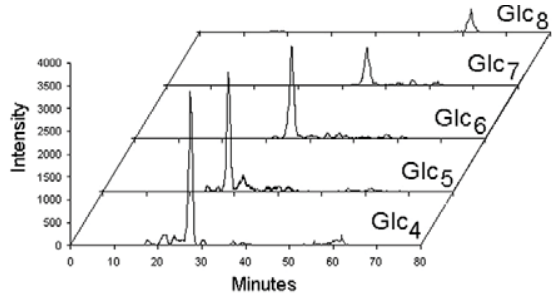

(b)

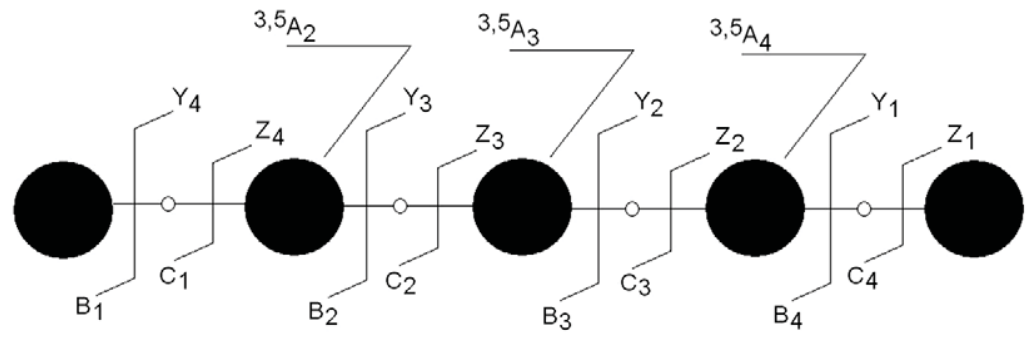

(c)

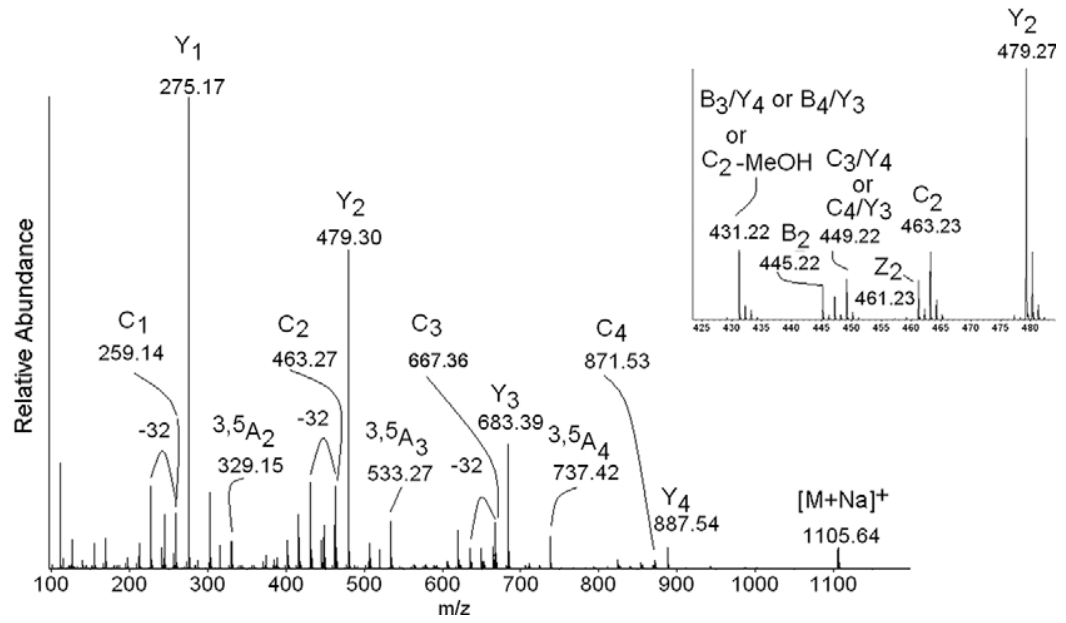

Figure 1. LC/MS analysis of permethylated malto-oligosaccharide alditols. (a) Extracted ion chromatograms of permethylated oligosaccharide alditol malto-oligosaccharide series $\mathrm{Glc}_{4-8}$. The Glc $\mathrm{C}_{4}$ $\mathrm{Glc}_{5} \mathrm{Glc}_{6}, \mathrm{Glc}_{7}[\mathrm{M}+\mathrm{Na}]^{+}$ions, $\mathrm{Glc}_{8}[\mathrm{M}+2 \mathrm{Na}]^{2+}$ were detected at $\mathrm{m} / \mathrm{z} 901.45,1105.56,1309.66$, 1513.76, and 870.43, respectively. Integrated peak areas are proportional to abundances of the glycoforms. (b) and (c) Fragment origin and CID QoTOF MS/MS spectra of Glc5, [M $+\mathrm{Na}^{+} \mathrm{m} / \mathrm{z}$ 1105.56. Fragmentation nomenclature is that of Domon and Costello [39]. All fragments contain sodium. Monosaccharide component symbols are those suggested by Varki et al. [40]. Key ions are indicated. The inset in (c) demonstrates that distinct $\mathrm{B}, \mathrm{Z}, \mathrm{C}$, and $\mathrm{Z}$ ions are produced from the reduced and permethylated hexose oligosaccharide. 
is shown in Figure 1c. For the malto-oligosaccharides, permethylation without prior reduction resulted in isobaric $Y$ and $C$ as well as $Z$ and $B$ ions. This situation was avoided by carrying out reduction before permethylation. As seen in the Figure $1 \mathrm{c}$ inset, $\mathrm{Y}$ and $\mathrm{C}$ and $\mathrm{Z}$ and $B$ ions are all unique $[3,5] . A_{n}(n=2,3,4)$ cross-ring fragments were observed at $\mathrm{m} / \mathrm{z} 329.12,533.27$ and 737.42 , respectively, thus confirming each $\beta 1,4$ glycosidic bond in the series. Also observed were secondary (internal) fragments such as the $Y_{4} / C_{3}$ and $Y_{3} / C_{4}$ fragment at $m / z$ 449.22. Fragments that correspond to methanol loss from the $C_{n}$ ion, e.g., $m / z$ 431.22, could also be assigned as $Y_{4} / B_{3}$ or $Y_{3} / B_{4}$. The presence of the abundant peak at $\mathrm{m} / \mathrm{z} 839.51$ indicated that the methanol loss is important for $C_{4}$ but the facile $B_{n}$ and $Y_{n}$ pathways suggest that, at lower $m / z$ values, the $Y_{x} / B_{y}$ isomer may be dominant. Therefore, for simplicity, in the following sections these types of fragments will be referred to as the $Y_{x} / B_{y}$ type. These data demonstrate the capacity of PGC to separate permethylated maltooligosaccharide alditols and also show the capacity of the method to provide informative fragmentation patterns where linkage, branch number, and sequence can be completely assigned.

\section{Porous Graphite LC/MS of High Mannose $N$-Glycans from RNase B}

Permethylated high mannose $N$-glycans have been studied by tandem mass spectrometry and their fragmentation patterns are well established [42, 43]. RNase B contains exclusively high mannose oligosaccharides. While some variation can be expected from differences in the protein source, method of release, and purification, the approximate abundance of each glycan size is known, as is the relative distribution of the isomers within each size pool [44, 45]. $\mathrm{Man}_{5} \mathrm{GlcNAc}_{2}$ and $\mathrm{Man}_{6} \mathrm{GlCNAc}_{2}$ are reported to be $\sim 57 \%$ and $\sim 31 \%$, respectively, of the total glycans of RNase B, and proton NMR has established that each is present as a single glycoform. There are three $\mathrm{Man}_{7} \mathrm{GlNAAc}_{2}$ isomers, which combined are $\sim 4 \%$ of total glycans. The isomers are referred to as D1, D2, and D3 and differ only in the position of one $\alpha 1,2 \mathrm{Man}$ residue (Figure 2). D1 refers to substitution of the $\alpha 1,2 \mathrm{Man}$ lower arm, D2 the central $\alpha 1,3 \mathrm{Man}$ arm, and D3 the upper $\alpha 1,6 \mathrm{Man}$ arm. The D1, D2, and D3 isomers are present in approximately equimolar proportions. $\mathrm{Man}_{8} \mathrm{GlcNAc}_{2}$ is reported to be $\sim 7 \%$ of total glycans and is also present as three isomers. The D1D3 isomer is most abundant and is $\sim 80 \%$ to $85 \%$ of $\mathrm{Man}_{8} \mathrm{GlcNAc}_{2}$. The D1D2 isomer is $\sim 10 \%$ to $15 \%$, and the D2D3 isomer is $\sim 5 \%$ of the total $\mathrm{Man}_{8} \mathrm{GlCNAc}_{2}$. Man ${ }_{9} \mathrm{GlCNAc}_{2}$ is $\sim 1 \%$ of glycans and is present as a single isoform. High mannose glycan was released from $\sim 2 \mathrm{mg}$ of lyophilized ribonuclease $\mathrm{B}$ powder. Approximately $120 \mu \mathrm{g}$ of mannan was obtained giving a yield of $\sim 80 \%$ based on $100 \%$ glycosylation site occupancy and an average oligosaccharide molecular weight of 1320 using a weighted average for glycans present.

To the LC/MS system equipped with a $2 \times 50 \mathrm{~mm}$ PGC column, $\sim 350$-ng aliquots of permethylated RNase $\mathrm{N}$-glycan alditols were applied, providing an estimated dynamic range in chemically distinct glycoforms of $\sim 200$ to $5.25 \mathrm{ng}$. The extracted ion chromatogram (XIC) of the RNase B Man ${ }_{5-9} \mathrm{GlCNAc}_{2}$ is shown in Figure 3a. Permethylation renders oligosaccharides within the same compound class nearly chemically equivalent. As a result, mass spectral responses are similar over a fairly broad mass range [46]. Integration of all ions from three independent experiments provided a distribution of $\mathrm{Man}_{5-9} \mathrm{GlCNAc}_{2}$ that was comparable to previous estimates determined by NMR and CE analyses [44, 45] as shown in Table 1. The chromatographic positions of each isomer in $\mathrm{Man}_{7} \mathrm{GlcNAc}_{2}$ and $\mathrm{Man}_{8} \mathrm{GlcNAc}_{2}$ are shown in Figure 3b.

The CID spectra of the three $\mathrm{Man}_{7} \mathrm{GlcNAc}_{2}$ isomers produced during a representative experiment are shown in Figure 2. The CID spectrum of $\mathrm{Man}_{7} \mathrm{GlcNAc}_{2}$, $[\mathrm{M}+2 \mathrm{Na}]^{2+} \mathrm{m} / \mathrm{z} 1013.49$, in the time domain 17.05 to $17.26 \mathrm{~min}$ is shown in Figure 3a. The derived structure and all key fragments are shown to the right of the spectrum. The ions seen at $\mathrm{m} / \mathrm{z} 1288.60$ and 1492.72 are consistent with fragments $Y_{3 \beta} / B_{5}$ for the former and $Y_{4 x} / B_{5}$ and $Y_{5 \alpha^{\prime}} / B_{5}$ for the latter, and define an upper arm that contained four Hex residues. Cross ring fragments ${ }^{0,4} \mathrm{~A}_{4}$ and ${ }^{3,5} \mathrm{~A}_{4}$ at $\mathrm{m} / z 913.47$ and 941.49 define the 1,6-linked arm. Both D2 and D3 isomers can contain these fragments. Prediction of the fragmentation of the D2 structure would forecast the presence of ${ }^{0,4} \mathrm{~A}_{3 \alpha}$ and ${ }^{3,5} \mathrm{~A}_{3 \alpha}$ fragments at $\mathrm{m} / \mathrm{z} 301.1$ and 329.1 , whereas fragmentation of the D3 structure should yield ${ }^{0,4} \mathrm{~A}_{3 c}$ and ${ }^{3,5} \mathrm{~A}_{3 \alpha}$ fragments at $m / z 505.2$ and 533.2. Indeed, fragments are observed at $\mathrm{m} / \mathrm{z} 301.15$ and 329.17 and not at $\mathrm{m} / \mathrm{z} 505.2$ or 533.2 , demonstrating that, in this time domain, the D2 isomer is the major isomer present. Thus, the partially resolved peak centered at $17.1 \mathrm{~min}$ is isomer D2.

The CID spectrum of the time domain 17.93 to 18.13 min is shown in Figure 3b. As in the D2 spectra, ions were observed at $m / z 1288.60$ for $\mathrm{Y}_{3 \beta} / \mathrm{B}_{5}$, and $\mathrm{m} / \mathrm{z}$ 1492.72 for $Y_{4 x} / B_{5}$ and $Y_{5 \alpha} / B_{5}$. As described above, these fragments are consistent with the presence of a branch that contained four Hex units. Cross-ring fragments ${ }^{0,4} \mathrm{~A}_{4}$ and ${ }^{3,5} \mathrm{~A}_{4}$ at $\mathrm{m} / \mathrm{z} 913.47$ and 941.49 were also observed. These define the $\mathrm{Man}_{4}$ branch as linked to the 1,6 arm. However, ${ }^{0,4} \mathrm{~A}_{3 \varkappa}$ and ${ }^{3,5} \mathrm{~A}_{3 \varkappa}$ fragments were detected at $\mathrm{m} / \mathrm{z} 505.24$ and 533.27 and not at $\mathrm{m} / \mathrm{z} 301.1$ and 329.1. Therefore, the predominant glycan in this time domain was the D3 isomer. The derived structure and the origins of all key fragment ions are shown to the right of the spectrum.

The CID spectrum of the time domain 19.02 to 19.23 $\mathrm{min}$ is shown in Figure 3c. An ion is observed at $\mathrm{m} / \mathrm{z}$ 1084.54, which is consistent with a $Y_{3 x} / B_{5}$ secondary fragment. This ion can not be generated by either isomer D2 or D3. The D1 $\alpha 1,6$ arm can be defined by 


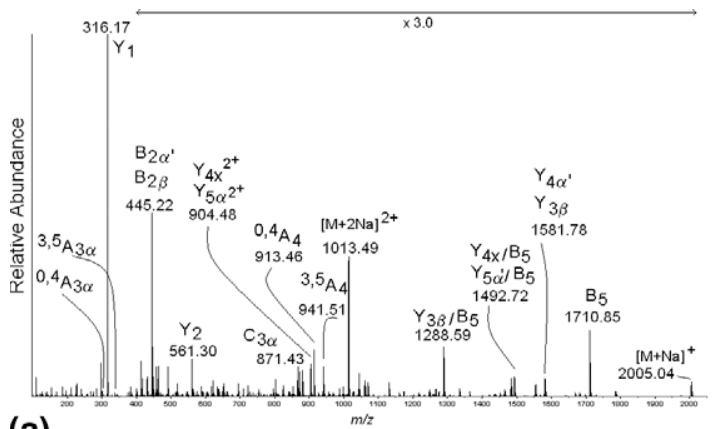

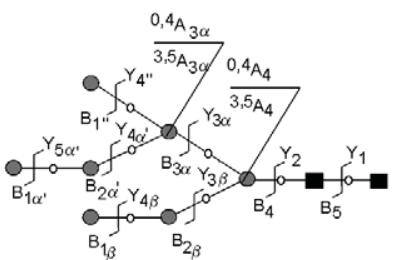

D2

(a)
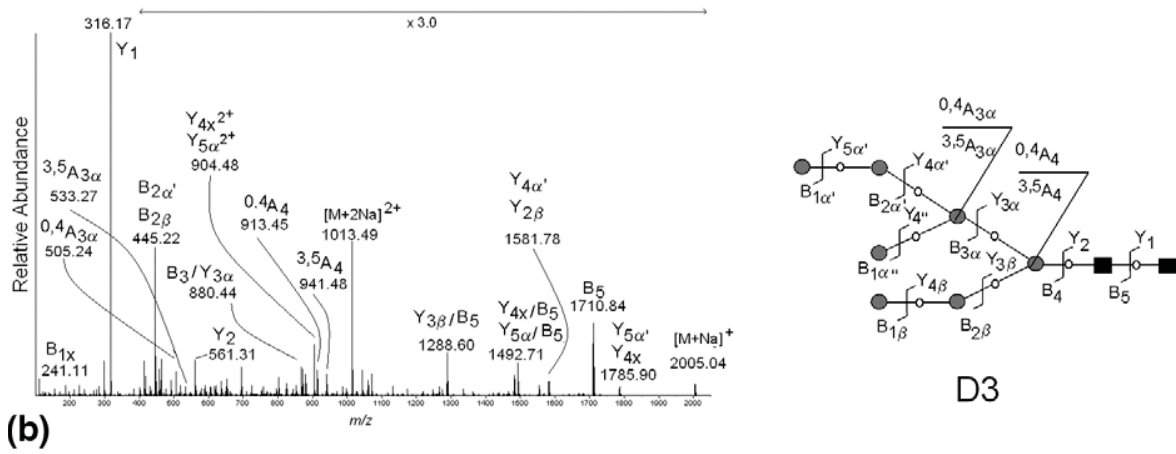

D3
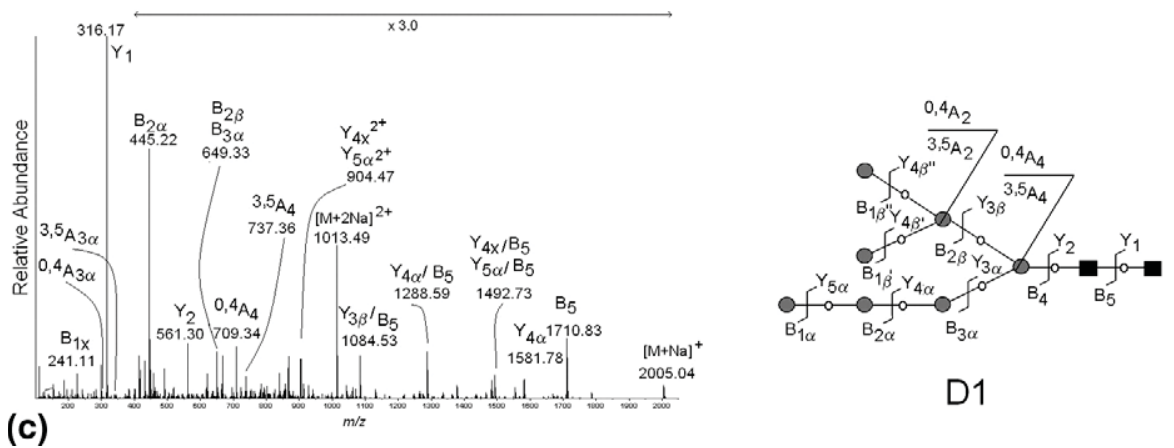

D1

Figure 2. CID QoTOF MS/MS spectra of $\mathrm{Man}_{7} \mathrm{GlcNAc}_{2} \mathrm{D} 1, \mathrm{D} 2$, and D3 isomers. Major product ions, derived from $[\mathrm{M}+2 \mathrm{Na}]^{2+} \mathrm{m} / \mathrm{z} 1013.49$ are indicated in each spectrum and their origins depicted to the structural representations to the right of each spectrum. Spectra and structural diagrams are shown in the order of their elution: (a) $\mathrm{Man}_{7} \mathrm{GlCNAc}_{2}$ D2; (b) Man $\mathrm{GlcNAc}_{2}$ D3, and (c) Man $\mathrm{GlcNAc}_{2}$ D1. All fragments contain sodium.

cross-ring fragments ${ }^{0,4} \mathrm{~A}_{3 \mathrm{a}},{ }^{3,5} \mathrm{~A}_{3 a}{ }^{0,4} \mathrm{~A}_{4}$, and ${ }^{3,5} \mathrm{~A}_{4}$, all of which are present in the spectrum at $m / z$ 301.18, 329.17, 709.34 , and 737.35, respectively. Thus, the predominant isomer within this time domain is the D1 isomer.

An XIC of the $\mathrm{Man}_{9} \mathrm{GlcNAc}_{2}[\mathrm{M}+2 \mathrm{Na}]^{2+}$ at $\mathrm{m} / \mathrm{z}$ 1217.63 is shown in Figure 2c from an analysis of a $20 \mathrm{ng}$ aliquot of total mannan using a $0.32 \times 100 \mathrm{~mm}$ PGC column. Nearly identical tandem mass spectra were obtained across the entire peak region supporting the presence of only one isomer as expected (not shown). An estimated $160 \mathrm{fmol}$ of $\mathrm{Man}_{9} \mathrm{GlcNAc}_{2}$ was present in the mixture and its mass spectrum is shown in the inset in Figure 2c. The signal-to-noise ratio was over 8000:1. When the amount of mannan was reduced 4-fold, a signal-to-noise ratio of over 500:1 was obtained from $\sim 40 \mathrm{fmol}$ of $\mathrm{Man}_{9} \mathrm{GlcNAc}_{2}$ (data not shown).

\section{Porous Graphite LC/MS of Articular Cartilage Decorin N-Glycans}

Decorin is a small leucine-rich proteoglycan of the extracellular matrix involved in cellular proliferation, migration, and phenotype. $\mathrm{N}$-glycosylation is thought to be required for its secretion $[47,48]$. Bovine articular cartilage decorin (ACD) $\mathrm{N}$-glycans are diverse and some contain antennae with LacdiNAc and fucosyl LacdiNAc and the core can be fucosylated or nonfucosylated. A thorough characterization of ACD N-glycans will be presented in detail in a manuscript currently in preparation by Contado-Miller et al.

ACD is a particularly challenging glycoprotein to analyze, as it contains chondroitin and/or dermatan sulfate as well as $\mathrm{N}$-glycan chains. The intact molec- 



(c)



(b)

Figure 3. Extracted ion chromatogram of permethylated oligosaccharide alditols $\mathrm{Man}_{5-9} \mathrm{GlcNAc}_{2}$ : (a) A stacked plot of molecular ions for $\mathrm{Man}_{5-9} \mathrm{GlcNAc}_{2}$ is shown; (b) three partially overlapping peaks are observed for $\mathrm{Man}_{7} \mathrm{GlcNAc}_{2}$ detected at $[\mathrm{M}+$ $2 \mathrm{Na}]^{2+} \mathrm{m} / \mathrm{z} 1013.49$ (bottom) and are labeled as D1, D2, and D3 and three are observed for $\mathrm{Man}_{8} \mathrm{GlcNAc}_{2}$ detected at $[\mathrm{M}+2 \mathrm{Na}]^{2+}$ $\mathrm{m} / \mathrm{z} 1115.55$ and are labeled as D1D2, D2D3, and D1D3 (top); (c) selected ion chromatogram of $\mathrm{Man}_{9} \mathrm{GlcNAc}_{2}$ produced from $\sim 160$ $\mathrm{fmol}$. The molecular ion region of the mass spectrum is shown in the inset. See text for details concerning nomenclature.

ular weight averages $\sim 100 \mathrm{kDa}$, of which $\sim 60 \%$ is glycosaminoglycan (GAG). There are three potential glycosylation sites. The $\mathrm{N}$-glycosylation site prediction algorithm NetNGlc 1.0 predicts only two are occupied. The actual site occupancy is not known. In processing, first the GAG must be removed, followed by the $\mathrm{N}$-glycan. Thus, considerable handling of the glycoprotein is required. For this study, $\sim 25 \mu \mathrm{g}$ of $\mathrm{AC}$ decorin was used. Based on total ion intensity compared to permethylated malto-oligosaccharide standard, MALDI-TOF spectra of the permethylated AC decorin $\mathrm{N}$-glycans indicated that 1 to $1.5 \mu \mathrm{g}$ of glycan material was released. This is approximately a $70 \%$ yield base on an average of $75 \%$ site occupancy and a composite average molecular weight glycan of 2000 Da.

In the analysis of decorin glycans carried out as part of the investigation reported here, two $\mathrm{dHex}_{1} \mathrm{Hex}_{4} \mathrm{HexNAc}_{4}$ isomers were detected. The isomers eluted at 18.6 and $29.1 \mathrm{~min}$, as shown in Figure 4 , and are labeled as Peaks A and B, respectively. CID data were collected for the apparent Fuc $_{1}$ Man $_{4}$ GalNAc $_{1}$ GlcNAc $_{4}[\mathrm{M}+2 \mathrm{Na}]^{2+}$ ion, $\mathrm{m} / \mathrm{z}$ 1039.56, detected from 18.36 to $18.56 \mathrm{~min}$. The monosaccharide composition proposed was based on GC/MS monosaccharide analysis of the trimethylsilylated derivatives (manuscript in preparation). The CID spectrum is shown in Figure 4b. Fragments were consistent with a hybrid-type glycan. The core is clearly defined as the unsubstituted chitobiose by the $Y_{1}$ and $Y_{2}$ fragments observed at $\mathrm{m} / \mathrm{z} 316.16$ and 561.27, respectively. The glycan was a hybrid type with a high mannose-type upper arm, as evidenced by the $B_{2 \beta}$ fragment at $m / z 445.22$ and secondary fragments $Y_{3 \alpha} / B_{5}$ and $\mathrm{Y}_{4 \alpha} / \mathrm{B}_{5}$ at $\mathrm{m} / \mathrm{z} 880.44$ and 1084.52. Other fragments that supported a high mannose hybrid-type upper arm were ${ }^{0,4} \mathrm{~A}_{4}$ and ${ }^{3,5} \mathrm{~A}_{4}$ fragments seen at $\mathrm{m} / \mathrm{z} 505.24$ and 533.26. Potential ${ }^{0,4} \mathrm{~A}$ or ${ }^{3,5} \mathrm{~A}$ type fragments were not observed at the calculated $\mathrm{m} / \mathrm{z}$ value of 301.1 and 329.1. Therefore, the terminal Man is not likely to be 1,6-linked and is likely 1,3-linked, resulting from incomplete trimming by mannosidases in the Golgi, the lower arm contained a dHex ${ }_{1} \mathrm{HexNAc}_{2}$ extension; this assignment is supported by the presence of a $B_{2 \beta}$ fragment at $\mathrm{m} / \mathrm{z}$ 701.35. $\mathrm{A} \mathrm{B}_{1 \alpha^{\prime}}$ fragment was observed at $\mathrm{m} / z 282.13$ and is consistent with a terminal HexNAc. The presence of internal dHex-HexNAc is supported by a $\mathrm{Y}_{5 \alpha^{\prime}} / \mathrm{B}_{2 \alpha}$ fragment observed at $m / z$ 442.22. The 3-O fucosyl substitution is supported by a $\mathrm{Y}_{5 \alpha^{\prime}} / \mathrm{B}_{5} / \mathrm{E}_{1 \alpha^{\prime \prime}}$ fragment at $\mathrm{m} / \mathrm{z}$ 1297.58, which has undergone a C-3 elimination of O-Fuc. Such fragmentations have been previously reported [17-19]. The derived structure is shown to the right of the spectrum and the origins of key fragments are indicated.

CID data were collected for the second $\mathrm{Fuc}_{1} \mathrm{Man}_{4} \mathrm{GalNAc}_{1} \mathrm{GlcNAc}_{3}[\mathrm{M}+2 \mathrm{Na}]^{2+}$ ion, $\mathrm{m} / \mathrm{z}$

Table 1. Comparison of semiquantitative methods for the analysis of RNase B oligosaccharides

\begin{tabular}{|c|c|c|c|c|c|}
\hline \multirow[b]{2}{*}{ Glycan } & \multicolumn{2}{|c|}{$\%$ Abundance LC/MS } & \multicolumn{2}{|c|}{$\%$ Abundance NMR ${ }^{a}$} & \multirow[b]{2}{*}{$\%$ Isomer abundance $\mathrm{CE}$} \\
\hline & Overall & Isomer & Overall & Isomer & \\
\hline $\mathrm{Man}_{5} \mathrm{GlcNAc}_{2}$ & $55.1 \pm 6.2$ & - & 57 & - & - \\
\hline $\operatorname{Man}_{6} \mathrm{GlcNAc}_{2}$ & $30.8 \pm 5.2$ & - & 31 & - & - \\
\hline $\mathrm{Man}_{7} \mathrm{GlcNAc}_{2} \mathrm{D} 1$ & $3.5 \pm 1.3$ & 44 & 1.5 & 31 & 38 \\
\hline $\mathrm{Man}_{7} \mathrm{GlcNAc}_{2} \mathrm{D} 2$ & $2.7 \pm 1.3$ & 34 & 1.5 & 33 & 37 \\
\hline $\mathrm{Man}_{7} \mathrm{GlcNAc}_{2} \mathrm{D} 3$ & $1.8 \pm 0.7$ & 22 & 1.0 & 35 & 25 \\
\hline $\mathrm{Man}_{8} \mathrm{GlcNAc}_{2}$ D1D2 & $0.2 \pm 0.1$ & 3 & 0.4 & 10 & 17 \\
\hline $\mathrm{Man}_{8} \mathrm{GlcNAc}_{2}$ D2D3 & $0.3 \pm 0.1$ & 5 & 0.7 & 6 & 4 \\
\hline $\mathrm{Man}_{8} \mathrm{GICNAc}_{2}$ D1D3 & $4.8 \pm 0.6$ & 92 & 5.9 & 84 & 78 \\
\hline $\mathrm{Man}_{9} \mathrm{GlcNAc}_{2}$ & $1.6 \pm 0.4$ & - & 1.0 & - & - \\
\hline
\end{tabular}

Error is expressed as standard error of the mean calculated from three independent analyses.

aValues are from reference [49].

bValues are from reference [50]. 
1039.56, eluting from 29.918 to $30.119 \mathrm{~min}$. The spectrum is shown in Figure 4c. Assignment of core fucosylation was supported by a $Y_{1}$ fragment at $m / z$ 490.28. The presence of a LacdiNAc antenna was supported by fragments $\mathrm{B}_{1 \alpha^{\prime}}, \mathrm{B}_{2 \alpha^{\prime}}, \mathrm{Z}_{3 \alpha^{\prime}}$ and $\mathrm{Y}_{4 \varkappa}$ at $m / z 282.13,527.28$, 1329.56 , and 1551.98, respectively. Evidence for a high mannose-type upper arm included cross ring fragments ${ }^{0,4} \mathrm{~A}_{4}$ and ${ }^{3,5} \mathrm{~A}_{4}$ at $m / z 505.24$ and 533.29, which define the 1,6-linked upper arm. Secondary fragmentation ions $\mathrm{Y}_{3 \alpha} / \mathrm{B}_{5 \alpha}$ and $\mathrm{Y}_{4 \alpha} / \mathrm{B}_{5 \alpha}$ at $\mathrm{m} / \mathrm{z} 880.44$ and 1084.51 add further support for the hybrid structure. The derived structure is shown to the right of the spectrum.

\section{Porous Graphite LC/MS of Caenorhabditis elegans O-Glycans}

The C. elegans O-glycan used here was from a previous study [34] generated from $\sim 10-\mathrm{g}$ wet weight of nematodes. LC/MS analyses were performed on $\sim 20 \mathrm{ng}$ aliquots of permethylated alditols using the $300 \mu$ PGC column.

If the analytes are sufficiently separated by LC and/or there are no coincident isobaric product ions from different but coeluting parent ions, it is often useful to perform a pseudo $\mathrm{MS}^{3}$ experiment using QoTOF mass spectrometry. Here the voltage offset

(a)
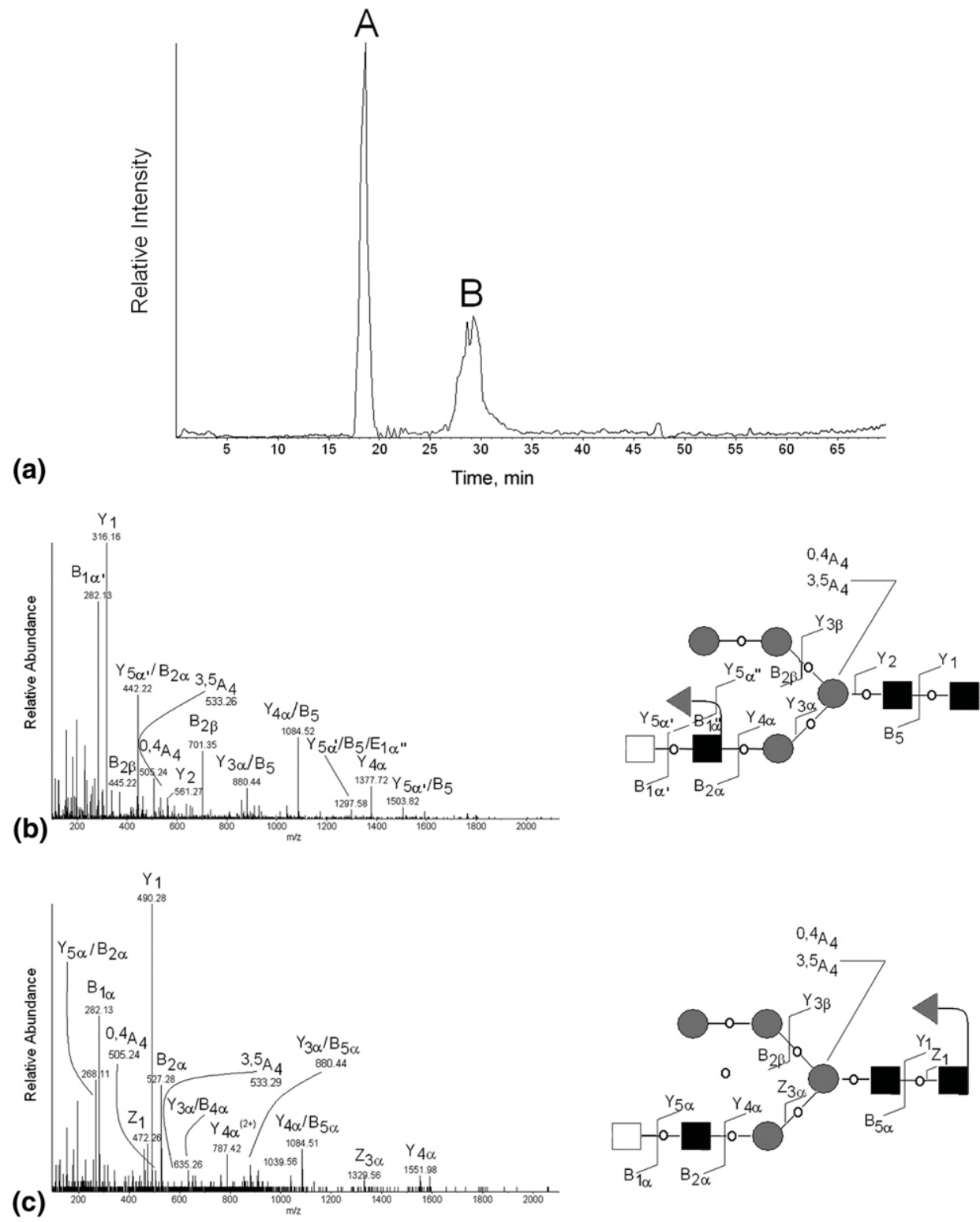

Figure 4. LC/MS analysis of articular cartilage decorin N-glycans. (a) The extracted ion chromatogram of articular cartilage decorin $\mathrm{dHex}_{1} \mathrm{Hex}_{4} \mathrm{HexNAc}_{4}$ permethylated oligosaccharide alditol is shown. Two well resolved peaks are observed for $[\mathrm{M}+2 \mathrm{Na}]^{2+} \mathrm{m} / \mathrm{z} 1039.56$ and are labeled as $\mathrm{A}$ and B; (b) and (c) CID QoTOF MS/MS spectra of articular cartilage decorin $\mathrm{dHex}_{1} \mathrm{Hex}_{4} \mathrm{HexNAc}_{4}$ permethylated oligosaccharide alditol isomers. The $[\mathrm{M}+2 \mathrm{Na}]^{2+}$ ions were isolated at $\mathrm{m} / \mathrm{z} 1039.56$. Key ions are indicated in each spectrum (a) and (c) and their origins are depicted in the structural representations to the right of each spectrum (b) and (c). All fragments contain sodium. 


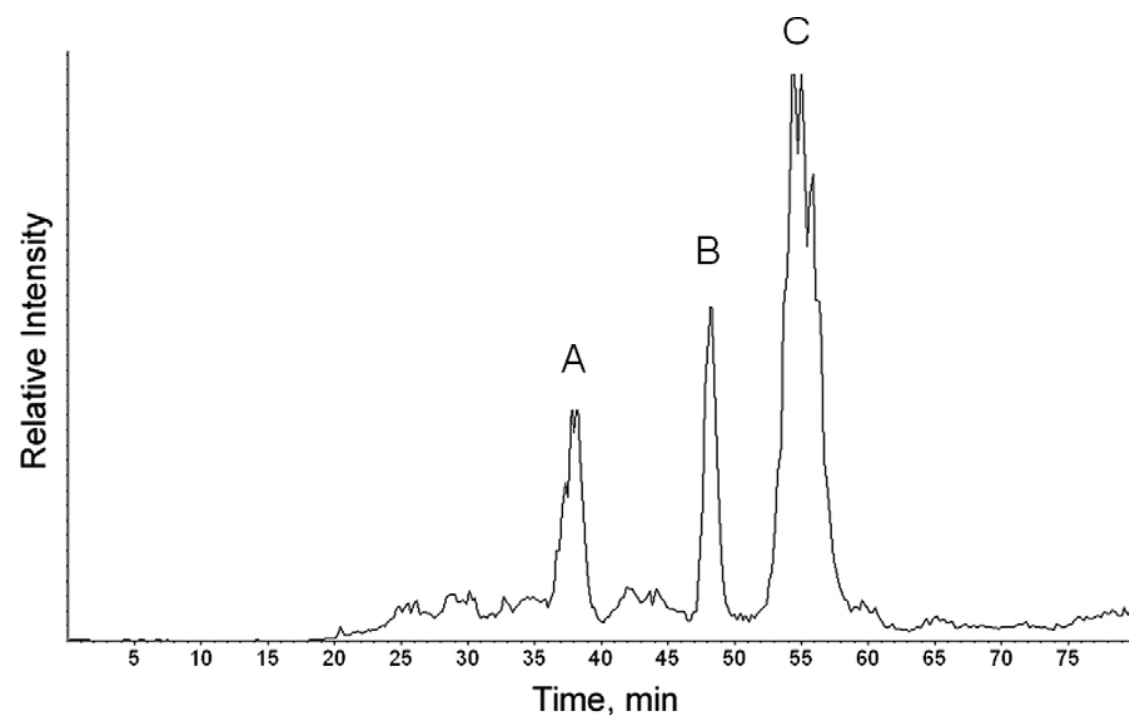

Figure 5. Trace ion chromatogram of reduced and permethylated C. elegans $\mathrm{Hex}_{3} \mathrm{HexNAc}_{1}$. Three major peaks are observed for $[\mathrm{M}+\mathrm{Na}]^{+} \mathrm{m} / z 942.55$ and are labeled as $\mathrm{A}, \mathrm{B}$, and $\mathrm{C}$.

relationships between the orifice, ring, skimmer, and $Q_{0}$ are set to favor prompt fragmentation. Results from ESI-TOF MS, MS ${ }^{2}$ and pseudo MS $^{3}$ experiments are presented below for the analysis of the C. elegans permethylated alditols, $\mathrm{Hex}_{3} \mathrm{HexNAc}_{1}$-ol O-glycan isomers.

C. elegans produces neutral $O$-glycans that contain a mammalian-like Gal $\beta 1,3 \mathrm{GalNAc}$ type I core and are highly branched and short [34, 49]. Both core residues can be highly substituted. The core Gal of the neutral O-glycans has been reported to be 4,6-disubstituted, while only GlcA has been reported to substitute the C-3 position [34,49]. The core GalNAc can be up to 3,4,6trisubstituted, whereas the $\mathrm{C}-3$ position has been reported to contain Gal exclusively [49]. The GalNAc C-6 position has been reported to be Gal- or Glc-substituted [49]. Mutant strains that are affected in O-glycan biosynthesis have altered susceptibilities to bacterial and fungal pathogens and are currently used to study host-pathogen interactions and innate immunity [34, $50-52]$. In the experiments reported here, the $\mathrm{O}$-glycans were chromatographically separated into neutral and acidic fractions before derivatization and analysis by LC/MS. The results for the neutral $O$-glycans are reported here. The XIC of $\mathrm{Hex}_{3} \mathrm{HexNAc}_{1}$-ol, $\mathrm{m} / z$ [M + $\mathrm{Na}]^{+}$942.55, is shown in Figure 5. Three major peaks, A, $\mathrm{B}$, and $\mathrm{C}$, were observed and were centered at 38.0, 48.5, and $56.0 \mathrm{~min}$, respectively.

The summed CID spectrum of Peak A generated in the time domain 37.54 to $37.74 \mathrm{~min}$ is shown in Figure 6a. The derived oligosaccharide structure is shown to the right of the spectrum. The presence of a 3,4,6trisubstituted HexNAc is supported by secondary fragment $Y_{1 x} / Y_{1 y} / Z_{1 x}$ at $m / z$ 270.14. Individual Hex losses were observed at $\mathrm{m} / z 706.39$ and 724.41 for $Z_{1 x}$ and $Y_{1 x}$ fragments, respectively. The dominant $Z_{1 x}$ intensity likely results, in part, from a C-3 elimination of 1,3- linked Hex from the core HexNAc-ol [17-19]. The abundant fragment at $m / z 415.21$ results from formation of the secondary fragment $\mathrm{C}_{1 \mathrm{x}} / \mathrm{B}_{1 \mathrm{y}}$ with loss of $\mathrm{CH}_{3} \mathrm{NHCOCH}_{3}$. This was supported by the pseudo MS fragmentation of the $\mathrm{m} / \mathrm{z} 415.21$ fragment shown in Figure $7 \mathrm{a}$. Ions consistent with the C-3 cleavage are observed at $m / z 329.18$ for the ${ }^{3} \mathrm{~A}_{1}$ fragment. The fragment observed at $\mathrm{m} / \mathrm{z} 383.21$ may have resulted from a methanol loss which could take the form of a ${ }^{5} \mathrm{~A}_{1}$ fragment. Further support is given by the presence of $C_{1}$ and $\mathrm{Z}_{1}-\mathrm{CH}_{3} \mathrm{OH}$ ions at $\mathrm{m} / \mathrm{z} 259.16$ and 165.09. The derived structure is a highly branched 3,4,6-trisubstituted core1-type glycan as shown in Figure 6a.

The CID spectra of Peaks B and C generated in the time domains 47.80 to 48.00 and 55.22 to $55.42 \mathrm{~min}$ were similar, as shown in Figure $6 \mathrm{~b}$ and c. The isomers are both biantennary, as indicated by the observation of secondary fragments $Y_{1 x} / Z_{1 y}$ and $Z_{1 y} / Y_{1 x}$ at $m / z 284.15$. Evidence for the presence of a $\mathrm{Hex}_{2}$ arm in both spectra was supported by the appearance of the product ion at $m / z 463.25$, which was consistent with a $C_{2 \alpha}$ fragment. No ion intensity is observed at $\mathrm{m} / \mathrm{z} 270$ in either spectrum, consistent with the absence of a trisubstituted configuration. The abundant $Z_{1 \alpha}$ fragment ion at $\mathrm{m} / \mathrm{z}$ 502.29 likely reflects a C-3 elimination of the 1,3-linked disaccharide substituent. The presence of cross-ring fragments ${ }^{0,4} \mathrm{~A}_{2},{ }^{3,5} \mathrm{~A}_{2}$, and ${ }^{1,4} \mathrm{~A}_{2}$ at $\mathrm{m} / \mathrm{z} 301.13,329.16$, and 359.18 suggests that both 1,4 and 1,6 linkages could be present in the $\mathrm{Hex}_{2}$ moiety. Taken together, these isomers fit the general linkage configuration Hex14,6Hex1,3(Hex1-4,6)HexNAc-ol. Pseudo MS ${ }^{3}$ experiments were performed to resolve the remaining ambiguity in linkage assignment.

MS $^{2}$ CID spectra from both Peaks B and C contained the C-type fragment at $\mathrm{m} / \mathrm{z}$ 463.22. The pseudo $\mathrm{MS}^{3}$ analysis of both produced nearly identical spectra. A representative example is shown in Figure 7b. In addi- 


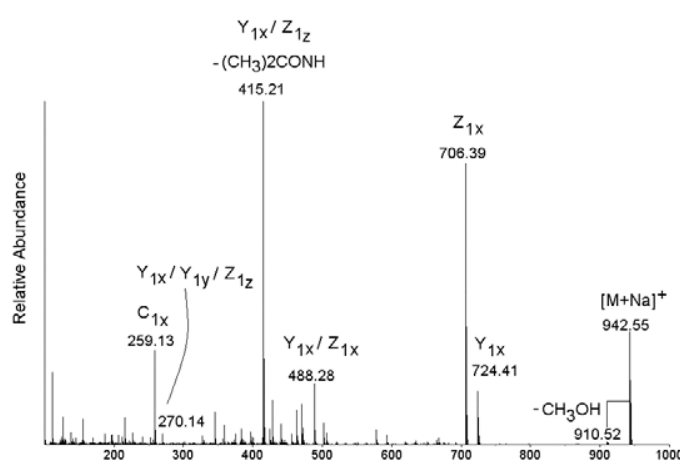

Peak A
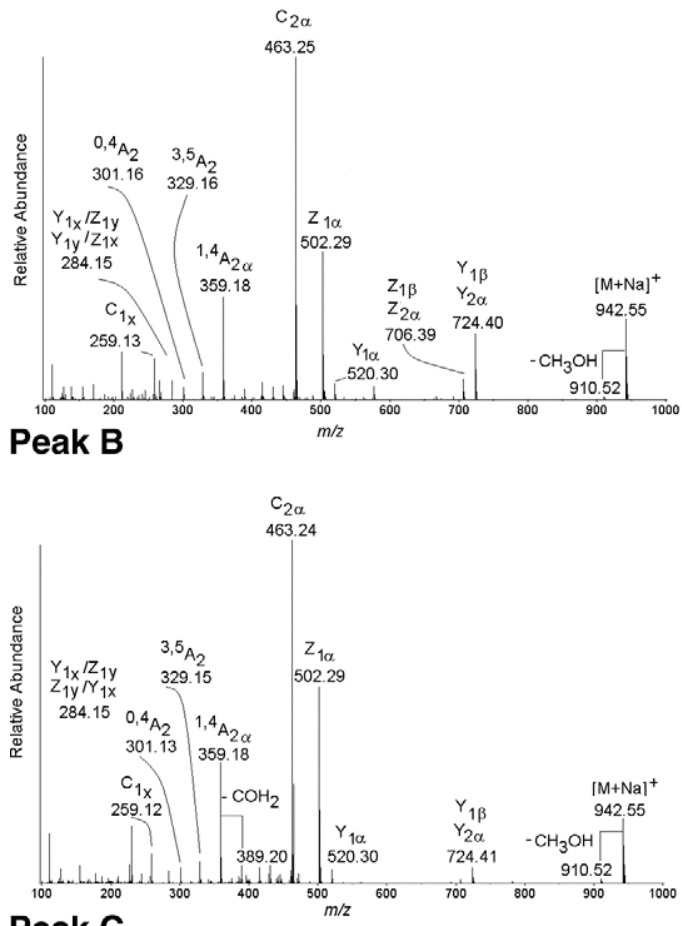

Peak C
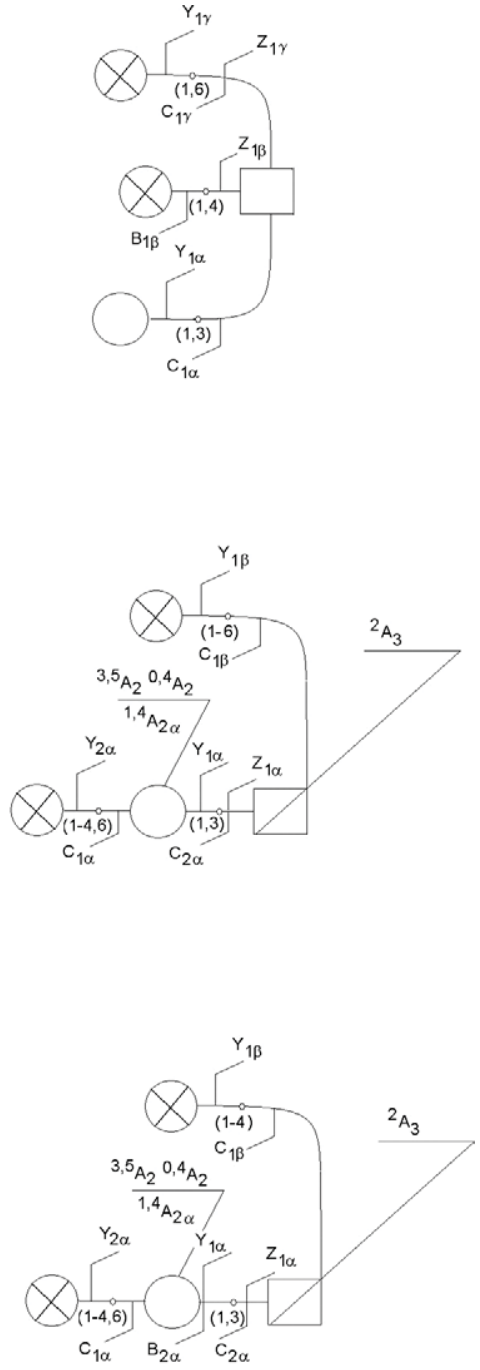

Figure 6. CID QoTOF MS/MS spectra of C. elegans $\mathrm{Hex}_{3} \mathrm{GalNAc}_{1}$ permethylated oligosaccharide alditol isomers isolated at $[\mathrm{M}+\mathrm{Na}]^{+} \mathrm{m} / z$ 942.55. The spectra of Peaks A, B, and $\mathrm{C}$ are shown. Key ions are indicated in each spectrum and their origins and resultant linkage assignments are depicted in the structural representations to the right of each spectrum. Peaks $B$ and $C$ each contained two isomers, the lower arm of which was either Hex1,4Hex1,3- or Hex1,6Hex1,3- linked to the core GalNAc-ol. Specific structural assignments are based on pseudo $\mathrm{MS}^{3}$ spectrum shown in Scheme 1. All fragments contain sodium. Monosaccharide identities are based on those of Varki et al. [40], as in other figures except that hexoses that can be either Gal or Glc are represented as circles with an X.

tion to glycosidic fragments $\mathrm{C}_{1}, \mathrm{Y}_{1}$ and $\mathrm{C}_{1}-\mathrm{CH}_{3} \mathrm{OH}$ observed at $\mathrm{m} / \mathrm{z} 259.12,245.09$ and 227.09 , respectively, cross-ring fragments were observed at $\mathrm{m} / \mathrm{z} 301.12$, 329.12, 359.17, and 389.17. A 1,4-linked pair can generate $\mathrm{m} / \mathrm{z} 329.12,359.17$, and 389.17 for ${ }^{3,5} \mathrm{~A}_{2},{ }^{1,4} \mathrm{~A}_{2}$ and ${ }^{0,2} \mathrm{~A}_{2}$ fragments. A 1,6-linked pair can generate $\mathrm{m} / \mathrm{z}$
$301.12,329.12$, and 389.17 for ${ }^{0,4} \mathrm{~A}_{2},{ }^{3,5} \mathrm{~A}_{2}$, and ${ }^{0,2} \mathrm{~A}_{2}$. The $\mathrm{m} / \mathrm{z} 301.12$ and 359.17 fragments are unique to the 1,6and 1,4-linked pairs, respectively. As the abundance of the $m / z 359.17$ fragment is very high, likely the majority of the disaccharide pair is present as the 1,4-linked pair with a minor component containing a 1,6-linked pair.

Figure 7. Pseudo MS $\mathrm{MS}^{3}$ spectra of key product ions of $\mathrm{Hex}_{3} \mathrm{GalNAc}_{1}$ permethylated alditol isomers. (a) ${ }^{3} \mathrm{X}_{2} \mathrm{~m} / \mathrm{z} 415.19$ ion of Peak A, B; $\mathrm{Z}_{1 \kappa} m / z 502.26$ ion for Peak B, C; $\mathrm{Z}_{1 \mathrm{a}} \mathrm{m} / \mathrm{z} 502.26$ ion for Peak C and D; ${ }^{1,4} \mathrm{~A}_{2 \alpha} \mathrm{m} / \mathrm{z} 463.22$ ion of Peak $C$. Proposed structures are shown above their spectra. In (b) and (c), the $\mathrm{Z}_{1 \alpha} \mathrm{m} / \mathrm{z} 502.26$ ion can be either a 1,4 or 1,6 glycosidic bond. See text for details. All fragments contain sodium. 

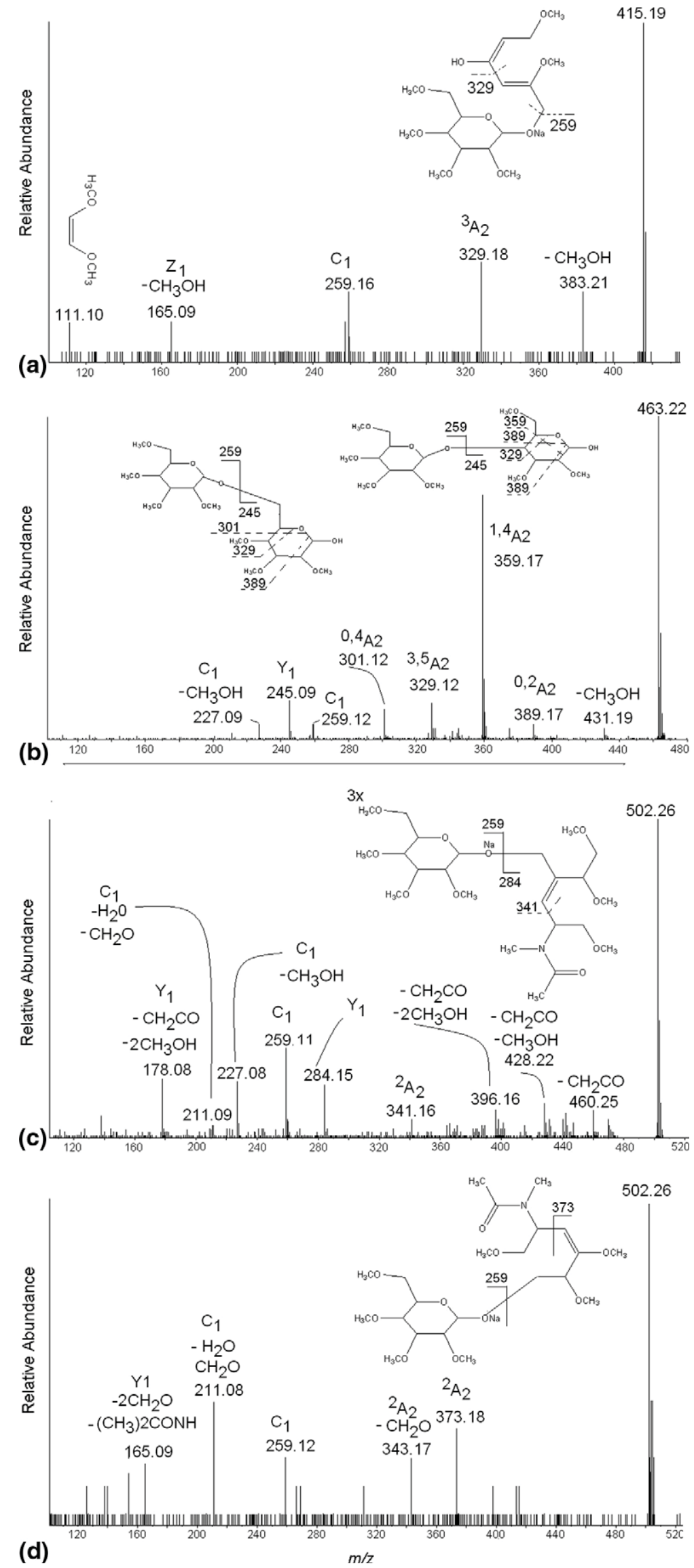


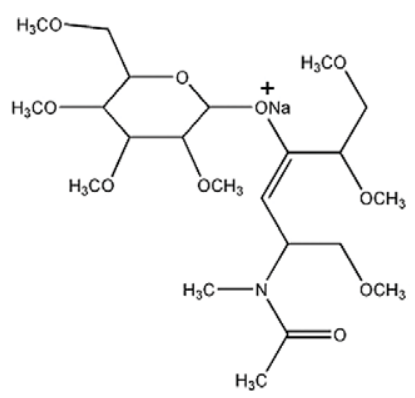

$m / z 502.263$

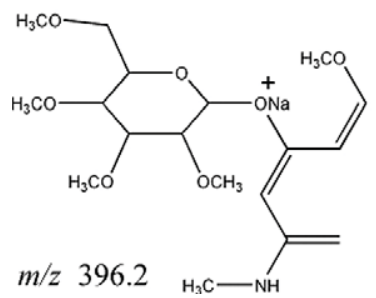

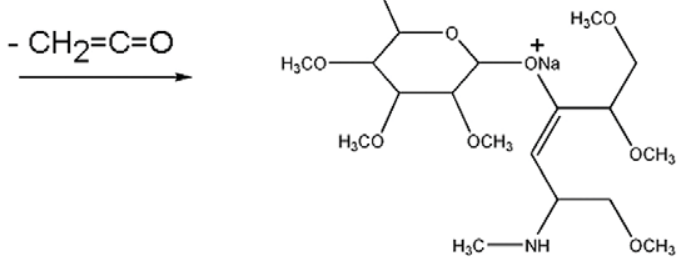

$m / z \quad 460.252$
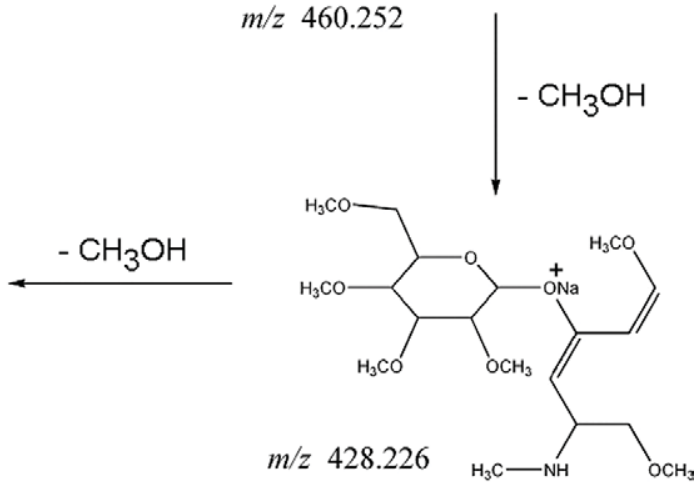

Scheme 1. Decomposition of the 1-4-linked disaccharide isolated at $m / z$ 502.26. The proposed pathway for the formation of key fragment ions is shown.

Therefore, two isomeric 1,3-linked $\mathrm{Hex}_{2}$ arms exist in each of Peaks B and C.

The C-type fragments isolated at $\mathrm{m} / \mathrm{z} 502.26$ in the respective time domains for Peaks $\mathrm{B}$ and $\mathrm{C}$ were also subjected to pseudo MS ${ }^{3}$ As shown in Figure 7c and d, each produced a unique spectrum. As each has undergone a C-3 substituent loss, only assignments to 1,4- or 1,6-linkages are possible. The pseudo $\mathrm{MS}^{3}$ spectrum produced from Peak $C$ is shown in Figure 7c. Loss of $\mathrm{CH}_{2} \mathrm{CO}$ (ketene) is observed at $\mathrm{m} / \mathrm{z} 460.25$ and is followed by two $\mathrm{CH}_{3} \mathrm{OH}$ losses shown by fragments observed at $\mathrm{m} / \mathrm{z} 428.22$ and 396.20. The authenticity of this series is supported by a $\mathrm{Y}_{1}$-type fragment that has lost $\mathrm{CH}_{2} \mathrm{CO}$ and two equivalents of $\mathrm{CH}_{3} \mathrm{OH}$, as seen at $\mathrm{m} / \mathrm{z}$ 178.08. These fragments likely originate from a 1,4-linked configuration, as rationalized in Scheme $\mathbf{1 .}$ The pseudo $\mathrm{MS}^{3}$ spectrum produced from Peak $\mathrm{C}$ is shown in Figure 7d. Fragments consistent with ${ }^{2} \mathrm{~A}_{2}$ and ${ }^{2} \mathrm{~A}_{2}-\mathrm{CH}_{2} \mathrm{O}$ were observed at $\mathrm{m} / \mathrm{z} 373.18$ and 343.17 . Fragments consistent with $\mathrm{C}_{1}$ and $\mathrm{C}_{1}$ with loss of $\mathrm{H}_{2} \mathrm{O}$ and $\mathrm{CH}_{2} \mathrm{O}$ were observed at $\mathrm{m} / \mathrm{z} 259.12$ and 211.08. A fragment was also observed at $\mathrm{m} / \mathrm{z} 165.09$, which is consistent with the presence of a $\mathrm{Y}_{1}$ fragment that has lost $\mathrm{CH}_{3} \mathrm{CONHCH}_{3}$ and two $\mathrm{CH}_{2} \mathrm{O}$ groups. It is known that in C. elegans the C- 6 position of the GalNAc core can be C-6 substituted with Hex as either Gal or Glc. Likely the $m / z 415.19$ fragment produced from Peak A contained a 1,6-linkage, as described previously. The pseudo $\mathrm{MS}^{3}$ spectrum of the $\mathrm{m} / \mathrm{z} 502.26$ fragment produced from Peak B was similar to that produced by the $\mathrm{m} / \mathrm{z} 415.19$ fragment of Peak A, in that both contained prominent fragments at $\mathrm{m} / \mathrm{z} 165.09$ and 259.12. The $\mathrm{m} / \mathrm{z}$ 502.26 fragment from Peak $C$ produced a spectrum that was different from both and arises from a 1,4-linked fragment ion. Therefore, likely both isomers in Peak B contain a 1,6-linked Hex, while isomers in Peak C contain a 1,4-linked Hex. Taken together, these data show that two major isomers exist in each peak. Both Peaks B and C contain isomers with Hex1,6Hex1,3- and Hex1,4Hex1,3- linked arms. Peak B contains a Hex1,6arm and Peak C contains a Hex1,4- arm. These tetrasaccharide assignments are consistent with the general structural paradigm seen in $O$-glycans that have been documented in C. elegans [34, 49]. The structural assignments are shown to the right of the spectra in Figure 6.

\section{Conclusions}

An LC/MS method for analysis of reduced and permethylated oligosaccharides has been developed that utilizes a porous graphite based LC system coupled with a QoTOF mass spectrometer. LC/MS separation and identification of permethylated oligosaccharide alditol isomers have been demonstrated for the first time. The method is rapid, reproducible and sensitive. When a $320-\mu \mathrm{m}$ column was used, $40 \mathrm{fmol}$ of oligosaccharide could be easily detected and fully characterized. Further reduction of chromatographic scale should significantly decrease the sample requirement.

The CID spectra of reduced and permethylated oligosaccharides provide informative fragmentation. The utility of permethylation in oligosaccharide structural determination is well documented. The linkage, branch, and sequence information provided in their fragmentation spectra is considered superior to most other derivatives. In the examples presented here, it is made clear that the utility of the highly informative CID spectra of permethylated oligosaccharides is enhanced by high- 
resolution liquid chromatography before introduction of the sample into the mass spectrometer since isomers are temporally resolved before ionization, thus reducing ambiguity in mass spectrometry-based structural assignments. Examples are given to demonstrate assignment of linkage and branch patterns in a variety of oligosaccharides ranging from linear to highly branched glycans and for both positional and branch isomers. Although the capacity of the system presented to differentiate isomers could be saturated by highly complex whole organism glycomes, the present system was employed successfully for structural assignments using up to the pseudo $\mathrm{MS}^{3}$ dimension. Further improvements to the LC system and additional levels of $\mathrm{MS}^{n}$ should enhance the capacity for glycoform resolution and assignment.

It is important to note that the method presented here has some inherent limitations. For some compounds, permethylation is not suitable. During permethylation, some labile groups such as $\mathrm{O}$-acetyl groups are lost and polar groups, such as phosphate and sulfate, can cause poor recovery during standard extractions used in the derivatization protocol. Therefore, if these substituents are suspected, an alternative approach should be considered. As with all chromatographic methods, resolution of the presented method is limited. Therefore, when highly complex mixtures are expected, prior sub-fractionation may be required. In its present form, the method is most useful for analysis of neutral saccharides up to those with tetra-antennary configurations. Those oligosaccharides that contain sialic acids tend to give broader peaks as the number of sialic acids increases.

Use of the permethylated derivatives for structural analysis of oligosaccharides is an active area of research. An online permethylation method was recently developed [53]. These authors demonstrate that oligosaccharides could be permethylated in minutes, reagents and byproducts could be efficiently removed and analytes directly introduced into an LC/MS system. Online derivatization coupled with LC/MS of permethylated oligosaccharide alditols has obvious advantages, and we are in the process of adapting online derivatization to the LC/MS platform. Reinhold et al. have recently reported the complete assignment of oligosaccharide structures of permethylated glycans using a database library, FragLib, in conjunction with their Oligosaccharide Subtree Constraint Algorithm (OSCAR) [38, 54, 55]. This algorithm incorporates analyst-selected $\mathrm{MS}^{n}$ ion fragmentation pathways for elucidation of oligosaccharide topology using a top-down sequencing strategy. Complete assignment was reported for a series of oligosaccharides, where mass, branch, linkage, diastereomerspecific composition, and anomeric configuration were determined. Undoubtedly, coupling of online derivatization, LC/MS, and bioinformatics will lead to even more facile structural assignment of oligosaccharides. This method will aid in efforts toward the overall goal of the bioanalyst to provide complete structural assign- ments for glycosylation details, even when sample material is limited.

\section{Acknowledgments}

The authors thank Dr. Patrick Van Roey of the Wadsworth Center, Albany NY, for the kind gift of the PNGase F plasmid used in this study. This work was supported by National Institutes of Health grants P41 RR10888 and S10 RR015942.

\section{References}

1. Apweiler, R.; Hermjakob, H.; Sharon, N. On the Frequency of Protein Glycosylation, as Deduced from Analysis of the SWISS-PROT Database. Biochim. Biophys. Acta 1999, 1473(1), 4-8.

2. Ben-Dor, S.; Esterman, N.; Rubin, E.; Sharon, N. Biases and Complex Patterns in the Residues Flanking Protein N-Glycosylation Sites. Glycobiology 2004, 14(2), 95-101.

3. Kornfeld, S. Diseases of Abnormal Protein Glycosylation: An Emerging Area. J. Clin. Invest. 1998, 101(7), 1293-1295.

4. Gorelik, E.; Galili, U.; Raz, A. On the Role of Cell Surface Carbohydrates and Their Binding Proteins (Lectins) in Tumor Metastasis. Cancer Metast. Rev. 2001, 20(3/4), 245-277.

5. Lowe, J. B. Glycan-Dependent Leukocyte Adhesion and Recruitment in Inflammation. Curr. Opin. Cell Biol. 2003, 15(5), 531-538.

6. Haltiwanger, R. S.; Lowe, J. B. Role of Glycosylation in Development. Annu. Rev. Biochem. 2004, 73, 491-537.

7. Lis, H.; Sharon, N. Protein Glycosylation. Structural and Functional Aspects. Eur. J. Biochem. 1993, 218(1), 1-27.

8. Laine, R. A. A calculation of All Possible Oligosaccharide Isomers Both Branched and Linear Yields $1.05 \times 10(12)$ Structures for a Reducing Hexasaccharide: The Isomer Barrier to Development of Single-Method Saccharide Sequencing or Synthesis Systems. Glycobiology 1994, 4(6), 759-767.

9. Freeze, H. H. Update and Perspectives on Congenital Disorders of Glycosylation. Glycobiology 2001, 11(12), 129R-143R.

10. Jaeken, J.; Matthijs, G. Congenital Disorders of Glycosylation. Annu. Rev. Genomics Hum. Genet. 2001, 2, 129-151.

11. Butler, M.; Quelhas, D.; Critchley, A. J.; Carchon, H.; Hebestreit, H. F.; Hibbert, R. G.; Vilarinho, L.; Teles, E.; Matthijs, G.; Schollen, E.; Argibay, P.; Harvey, D. J.; Dwek, R. A.; Jaeken, J.; Rudd, P. M. Detailed Glycan Analysis of Serum Glycoproteins of Patients with Congenital Disorders of Glycosylation Indicates the Specific Defective Glycan Processing Step and Provides an Insight into Pathogenesis. Glycobiology 2003, 13(9), 601-622.

12. Harvey, D. J. Matrix-Assisted Laser Desorption/Ionization Mass Spectrometry of Carbohydrates. Mass Spectrom. Rev. 1999, 18(6), 349-450.

13. Mechref, Y.; Novotny, M. V.; Krishnan, C. Structural Characterization of Oligosaccharides Using MALDI-TOF/TOF Tandem Mass Spectrometry. Anal. Chem. 2003, 75(18), 4895-4903.

14. Muzikar, J.; Mechref, Y.; Huang, Y.; Novotny, M. Enhanced Post-Source Decay and Cross-Ring Fragmentation of Oligosaccharides Facilitated by Conversion to Amino Derivatives. Rapid Commun. Mass Spectrom. 2004 18(13), 1513-1518.

15. Morelle, W.; Slomianny, M. C.; Diemer, H.; Schaeffer, C.; van Dorsselaer, A.; Michalski, J. C. Fragmentation Characteristics of Permethylated Oligosaccharides Using a Matrix-Assisted Laser Desorption/Ionization Two-Stage Time-of-Flight (TOF/TOF) Tandem Mass Spectrometer. Rapid Commun. Mass Spectrom. 2004, 18(22), 26372649.

16. Perreault, H.; Costello, C. E. Stereochemical Effects on the Mass Spectrometric Behavior of Native and Derivatized Trisaccharide Isomers: Comparisons with Results from Molecular Modeling. J. Mass Spectrom. 1999, 34(3), 184-197.

17. Viseux, N.; de Hoffmann, E.: Domon, B. Structural Assignment of Permethylated Oligosaccharide Subunits Using Sequential Tandem Mass Spectrometry. Anal. Chem. 1998, 70(23), 4951-4959.

18. Viseux, N.; de Hoffmann, E.; Domon, B. Structural Analysis of Permethylated Oligosaccharides by Electrospray Tandem Mass Spectrometry. Anal. Chem. 1997, 69(16), 3193-3198.

19. Morelle, W.; Faid, V.; Michalski, J. C. Structural Analysis of Permethylated Oligosaccharides Using Electrospray Ionization Quadrupole Time-of-Flight Tandem Mass Spectrometry and Deutero-Reduction. Rapid Commun. Mass Spectrom. 2004, 18(20), 2451-2464.

20. Delaney, J., Vouros, P. Liquid Chromatography Ion Trap Mass Spectrometric Analysis of Oligosaccharides Using Permethylated Derivatives. Rapid Commun. Mass Spectrom. 2001, 15, 325-334.

21. Novotny, M. V.; Mechref, Y. New Hyphenated Methodologies in High-Sensitivity Glycoprotein Analysis. J. Sep. Sci. 2005, 28(15), $1956-$ 1968.

22. Rudd, P. M.; Colominas, C.; Royle, L.; Murphy, N.; Hart, E.; Merry, A. H.; Hebestreit, H. F.; Dwek, R. A. A High-Performance Liquid Chromatography Based Strategy for Rapid, Sensitive Sequencing of N-Linked Oligosaccharide Modifications to Proteins in Sodium Dodecyl 
Sulphate Polyacrylamide Electrophoresis Gel Bands. Proteomics 2001, 1(2), 285-294.

23. Saba, J. A.; Shen, X. D.; Jamieson, J. C.; Perreault, H. Effect of 1-Phenyl3-Methyl-5-Pyrazolone Labeling on the Fragmentation Behavior of Asialo and Sialylated N-Linked Glycans Under Electrospray Ionization Conditions. Rapid Commun. Mass Spectrom. 1999, 13(8), 704-711.

24. Cipollo, J. F.; Awad, A. M.; Costello, C. E.; Hirschberg, C. B. N-Glycans of Caenorhabditis elegans are Specific to Developmental Stages. J. Biol. Chem. 2005, 280(28), 26063-26072.

25. Kawasaki, N.; Haishima, Y.; Ohta, M.; Itoh, S.; Hyuga, M.; Hyuga, S.; Hayakawa, T. Structural Analysis of Ssulfated N-Linked Oligosaccharides in Erythropoietin. Glycobiology 2001, 11(12), 1043-1049.

26. Wada, Y.; Tajiri, M.; Yoshida, S. Hydrophilic Affinity Isolation and MALDI Multiple-Stage Tandem Mass Spectrometry of Glycopeptides for Glycoproteomics. Anal. Chem. 2004, 76(22), 6560-6565.

27. Bruggink, C.; Maurer, R.; Herrmann, H.; Cavalli, S.; Hoefler, F. Analysis of Carbohydrates by Anion Exchange Chromatography and Mass Spectrometry. J. Chromatogr. A 2005, 1085(1), 104-109.

28. Tolstikov, V. V.; Fiehn, O. Analysis of Highly Polar Compounds of Plant Origin: Combination of Hydrophilic Interaction Chromatography and Electrospray Ion Trap Mass Spectrometry. Anal. Biochem. 2002, 301(2), 298-307.

29. Dage, J. L.; Ackermann, B. L.; Halsall, H. B. Site Localization of Sialyl Lewis $(x)$ Antigen on $x 1$-Acid Glycoprotein by High Performance Liquid Chromatography-Electrospray Mass Spectrometry. Glycobiology 1998, 8(8), 755-760.

30. Kawasaki, N.; Ohta, M.; Hyuga, S.; Hashimoto, O.; Hayakawa, T. Analysis of Carbohydrate Heterogeneity in a Glycoprotein Using Liquid Chromatography/Mass Spectrometry and Liquid Chromatography with Tandem Mass Spectrometry. Anal. Biochem. 1999, 269(2), 297-303.

31. Ninonuevo, M.; An, H.; Yin, H.; Killeen, K.; Grimm, R.; Ward, R. German, B.; Lebrilla, C. Nanoliquid Chromatography-Mass Spectrometry of Oligosaccharides Employing Graphitized Carbon Chromatography on Microchip with a High-Accuracy Mass Analyzer. Electrophoresis 2005, 26(19), 3641-3649.

32. Boulenguer, P.; Leroy, Y.; Alonso, J. M.; Montreuil, J.; Ricart, G.; Colbert, C.; Duquet, D. Dewaele, C. Fournet, B. Continuous-Flow Fast Atom Bombardment-Mass Spectrometry of Permethylated Oligosaccharides: A Comparative Study of Direct Mixture Analysis with Packed Capillary Column Liquid Chromatography-Fast Atom Bombardment-Mass Spectrometry. Anal. Biochem. 1988, 168(1), 164-170.

33. Verostek, M. F.; Lubowski,C.; Trimble, R. B. Selective Organic Precipitation/ Extraction of Released N-Glycans Following Large-Scale Enzymatic Deglycosylation of Glycoproteins. Anal. Biochem. 2000, 278(2), 111-122.

34. Cipollo, J. F.; Awad, A. M.; Costello, C. E.; Hirschberg, C. B. srf-3, a mutant of Caenorhabditis elegans, Resistant to Bacterial Infection and to Biofilm Binding, is Deficient in Glycoconjugates. J. Biol. Chem. 2004, 279(51), 52893-52903.

35. Ciucanu, I.; Kerek, F. A Simple and Rapid Method for the Permethylation of Carbohydrates. Carbohydr. Res. 1984, 131(2), 209-217.

36. Cipollo, J. F.; Costello, C. E.; Hirschberg, C. B. The fine structure of Caenorhabditis elegans N-Glycans. J. Biol. Chem. 2002, 277(51), $49143-$ 49157.

37. Sheeley, D. M.; Reinhold, V. N. Structural Characterization of Carbohydrate Sequence, Linkage, and Branching in a Quadrupole Ion trap Mass Spectrometer: Neutral Oligosaccharides and N-Linked Glycans. Anal. Chem. 1998, 70(14), 3053-3059.
38. Ashline, D.; Singh, S.; Hanneman, A.; Reinhold, V. Congruent Strategies for Carbohydrate Sequencing. 1. Mining Structural Details by MS $^{n}$. Anal. Chem. 2005, 77(19):6271-6279.

39. Domon, B.; Costello, C. E. A systematic Nomenclature for Fragmentations in FAB-MS/MS Spectra of Glycoconjugates. Glycoconj. J. 1988, 5, 397-409.

40. Varki, A.; Cummings, R.; Esko, J.; Freeze, H.; Hart, G.; Marth, G. Essentials of Glycobiology; Cold Spring Harbor Laboratory Press: Cold Spring Harbor, NY, 1999.

41. http://grtc.ucsd.edu/symbol.html

42. Stephens, E.; Maslen, S. L.; Green, L. G.; Williams, D. H. Fragmentation Characteristics of Neutral N-Linked Glycans Using a MALDI-TOF/TOF Tandem Mass Spectrometer. Anal. Chem. 2004, 76(8), 2343-2354.

43. Wuhrer, M.; Deelder, A. M. Matrix-Assisted Laser Desorption/Ionization In-Source Decay Combined with Tandem Time-of-Flight Mass Spectrometry of Permethylated Oligosaccharides: Targeted Characterization of Specific Parts of the Glycan Structure. Rapid Commun. Mass Spectrom. 2006, 20(6), 943-951.

44. Fu, D.; Chen, L.; O'Neill, R. A. A Detailed Structural Characterization of Ribonuclease B Oligosaccharides by 1H NMR Spectroscopy and Mass Spectrometry. Carbohydr. Res. 1994, 261(2), 173-186.

45. Guttman, A.; Pritchett, T. Capillary Gel Electrophoresis Separation of High-Mannose Type Oligosaccharides Derivatized by 1-Aminopyrene3,6,8-Trisulfonic acid. Electrophoresis 1995, 16(10), 1906-1911.

46. Reinhold, V. N.; Reinhold, B. B.; Costello, C. E. Carbohydrate Molecular Weight Profiling, Sequence, Linkage, and Branching Data: ES-MS and CID. Anal. Chem. 1995, 67(11), 1772-1784.

47. Seidler, D. G.; Faiyaz-Ul-Haque, M.; Hansen, U.; Yip, G. W.; Zaidi, S. H. Teebi, A. S.; Kiesel, L.; Gotte, M. Defective Glycosylation of Decorin and Biglycan, Altered Collagen Structure, and Abnormal Phenotype of the Skin Fibroblasts of an Ehlers-Danlos Syndrome Patient Carrying the Novel Arg270Cys Substitution in Galactosyltransferase I (B4GalT-7). I. Mol. Med. 2006, 84(7):583-954

48. Seo, N. S.; McQuillan, D. J.; Hook, M. The Role of Glycosylation in the Secretion of Proteoglycans. Sci. World J. 2006, 6, 491-493.

49. Guerardel, Y.; Balanzino, L.; Maes, E.; Leroy, Y.; Coddeville, B.; Oriol, R.; Strecker, G. The Nematode Caenorhabditis elegans Synthesizes Unusual O-Linked Glycans: Identification of Glucose-Substituted MucinType O-Glycans and Short Chondroitin-Like Oligosaccharides. Biochem. J. 2001, 357(Pt 1), 167-182.

50. Nicholas, H. R.; Hodgkin, J. Responses to Infection and Possible Recognition Strategies in the Innate Immune System of Caenorhabditis elegans. Mol. Immunol. 2004, 41(5), 479-493.

51. Gravato-Nobre, M. J.; Hodgkin, J. Caenorhabditis elegans as a Model for Innate Immunity to Pathogens. Cell Microbiol. 2005, 7(6), 741-751.

52. Silverman, M. A.; Blaxter, M. L.; Link, C. D. Biochemical Analysis of Caenorhabditis elegans Surface Mutants. J. Nematol. 1997, 29(3), 296-305.

53. Kang, P.; Mechref, Y.; Klouckova, I.; Novotny, M. V. Solid-Phase Permethylation of Glycans for Mass Spectrometric analysis. Rapid Commun. Mass Spectrom. 2005, 19(23), 3421-3418.

54. Lapadula, A. J.; Hatcher, P. J.; Hanneman, A. J.; Ashline, D. J.; Zhang, H.; Reinhold, V. N. Congruent Strategies for Carbohydrate Sequencing. 3. OSCAR: An Algorithm for Assigning Oligosaccharide Topology from $\mathrm{MS}^{n}$ Data. Anal. Chem. 2005, 77(19), 6271-6279.

55. Zhang, H.; Singh, S.; Reinhold, V. N. Congruent Strategies for Carbohydrate Sequencing. 2. FragLib: An $\mathrm{MS}^{n}$ Spectral Library. Anal. Chem. 2005, 77(19):6263-6270. 